\title{
Effect of Heat Treatments on Fatigue Properties of Ti-6Al-4V and 316 L Produced by Laser Powder Bed Fusion in As-Built Surface Condition
}

\author{
Antonio Cutolo, Chola Elangeswaran, Charlotte de Formanoir, \\ Gokula Krishna Muralidharan and Brecht Van Hooreweder
}

\begin{abstract}
Over the last decade, additive manufacturing (AM) techniques have been expanding rapidly due to their ability to produce complex geometries with an efficient use of material. In order to design reliable AM parts, the mechanical properties resulting from the manufacturing process need to be understood. The present study investigates the fatigue of AM Ti-6Al-4V and 316L. Miniaturized Ti-6Al-4V and 316L specimens were manufactured using laser powder bed fusion (L-PBF). The geometry, process parameters, and loading conditions were kept constant and the specimens were tested in as-built surface condition. The S-N curves of as-built, stressrelieved and HIP'ed specimens were measured, and an analysis of the microstructure, relative density and surface roughness was performed. The effect of fatigue influencing factors (residual stresses, surface roughness, porosity and microstructure) was systematically investigated. In order to understand the fatigue failure mechanism, identification of crack initiation point, via fracture surfaces analysis, was performed.
\end{abstract}

Keywords Laser powder bed fusion $\cdot \mathrm{Ti}-6 \mathrm{Al}-4 \mathrm{~V} \cdot 316 \mathrm{~L} \cdot$ Fatigue $\cdot$ Heat treatment

\section{Introduction}

Laser powder bed fusion (L-PBF), also known as selective laser melting (SLM), is an additive manufacturing (AM) technique that allows the production of metallic parts using a high-power laser that locally melts successive layers of powder. The L-PBF

\footnotetext{
A. Cutolo $(\bowtie) \cdot$ C. Elangeswaran · C. de Formanoir · B. Van Hooreweder Department of Mechanical Engineering, KU Leuven, Celestijnenlaan 300, 3001 Leuven, Belgium e-mail: antonio.cutolo@kuleuven.be
}

A. Cutolo · C. Elangeswaran

SIM M3 Program, Technologiepark 935, 9052 Zwijnaarde, Belgium

G. K. Muralidharan

3D Systems Leuven, Grauwmeer 14, 3001 Leuven, Belgium

(C) The Minerals, Metals \& Materials Society 2019

The Minerals, Metals \& Materials Society (ed.), TMS 2019 148th

Annual Meeting \& Exhibition Supplemental Proceedings, The Minerals, Metals \& Materials Series, https://doi.org/10.1007/978-3-030-05861-6_36 
technique has several advantages over conventional production techniques, such as a low material waste, a high level of flexibility and the ability to produce geometrically complex structural parts. The details and applications of this AM process have been widely reviewed $[1,2]$.

Due to their ability to fabricate customized parts with complex geometry, LPBF processes are increasingly used in many different industrial sectors, such as aerospace, biomedical and automotive industry. However, one of the major drawbacks of powder bed AM processes such as L-PBF is the very high surface roughness induced by the process [3]. This is particularly critical considering the fact that a customized SLM part, with a complex geometry, often has some areas with rough as-built surfaces, since in many cases, not all surfaces are accessible for polishing or machining. For that reason, this work focusses on the behavior of metal AM samples with as-built surface condition.

In order to exploit the benefits of AM techniques for safety-critical component production, the mechanical behavior of additively manufactured metals must be better understood. For this reason, fatigue of AM'ed parts is widely investigated in the literature. Leuders et al. [4] concluded that for Ti-6Al-4V manufactured by SLM, the main drivers for fatigue crack initiation and failure are internal defects, such as pores, acting like stress raisers. Kasperovich and Hausmann [5] found that hot isostatic pressing (HIP), by coarsening the microstructure and reducing porosity, leads to a significant improvement of ductility and fatigue strength of $\mathrm{Ti}-6 \mathrm{Al}-4 \mathrm{~V}$ processed by SLM. Therefore, they concluded that HIP is necessary for cyclically loaded components. Similar conclusions are reported by Ramulu and Edwards [6] who also indicated the need to perform heat treatments, i.e. stress-relief or HIP, on SLM Ti-6Al-4V in order to reduce the residual stress levels generated during manufacturing. In addition, they concluded that the effect of as-built surface condition on fatigue properties could not be determined due to the presence of internal defects and residual stress. Cao et al. [7] reported that fatigue properties of SLM Ti-6Al-4V are mostly controlled by surface roughness and defects that significantly reduce the fatigue strength of the material.

Austenitic $316 \mathrm{~L}$ exhibits very high ductility $[8,9]$ that helps reducing the local stress at defect sites and delaying crack initiation, hence reducing the influence of defects. This could explain the relatively good fatigue behavior of $316 \mathrm{~L}$ processed by L-PBF [8]. Spierings et al. [10] tested the fatigue behavior of SLM 316L, using post-machined specimens, and observed that the material was not very sensitive to pores and other defects. From a microstructural point of view, grain coarsening and homogenization through recrystallization induced by dedicated heat treatments were found to improve crack initiation behavior [11].

Examination of the state of the art shows that fatigue properties of L-PBF Ti-6Al-4V and 316L are mostly influenced by surface roughness, residual stresses produced during manufacturing, microstructure and pores. In order to exclude the influence of porosity from the scope of this investigation, the fatigue performances of L-PBF Ti-6Al-4V and 316L were measured on almost pore-free specimens. A systematic investigation of the influence of heat treatments on fatigue properties was performed on these specimens. 
Fig. 1 Fatigue sample geometry and dimensions

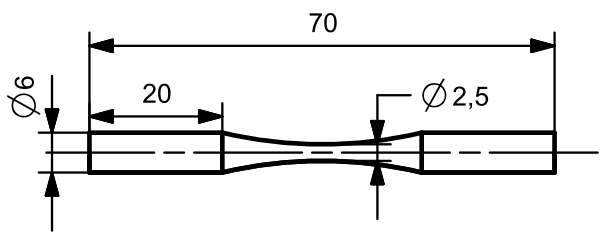

\section{Materials and Methods}

Fatigue specimens used in this investigation are miniaturized samples with a circular cross section and continuous radius between ends. These miniaturized test coupons were designed specifically for the fatigue testing of additively manufactured metals, taking into account the following considerations: (i) the radius between the two ends is optimized in order to reduce the impact of staircase effect on surface roughness [12]; (ii) the design ensures that failure always occurs in the smallest cross-sectional area, minimizing the scatter in fatigue data; (iii) buckling during axial compression loading is avoided; (iv) the gripping area is optimized for sufficient friction between the sample and the clamps; (v) the miniaturized geometry design reduces the production cost and time. Sample geometry and dimensions are shown in Fig. 1.

Miniaturized samples were manufactured via L-PBF on a ProX DMP320 machine (3D Systems) equipped with a $500 \mathrm{~W}$ Fiber laser using LaserForm Ti Grade 23 powder (3D Systems) for Ti-6Al-4V specimens and Laser Form 316L powder (3D Systems) for $316 \mathrm{~L}$ specimens. A layer thickness of $60 \mu \mathrm{m}$ was used for both Ti-6Al-4V and $316 \mathrm{~L}$ specimens. The test coupons were produced with the axis oriented in the building direction (i.e. $\mathrm{Z}$ axis).

Two different heat treatments were investigated for Ti-6Al-4V samples, namely, stress-relief (SR) and hot isostatic pressing (HIP): for SR, the samples were heated at $850{ }^{\circ} \mathrm{C}$ for $2 \mathrm{~h}$ followed by air cooling, while for HIP the samples were heated at a temperature of $920^{\circ} \mathrm{C}$ at a pressure of 1000 bar for $2 \mathrm{~h}$. For $316 \mathrm{~L}$ samples, only SR was performed, by heating the $316 \mathrm{~L}$ samples to $470{ }^{\circ} \mathrm{C}$ for $5 \mathrm{~h}$. In total, three different conditions were investigated for Ti-6Al-4V, i.e. as-built (ASB), SR, HIP and two conditions for $316 \mathrm{~L}$, i.e. ASB and SR. All the samples were tested in as-built surface condition.

For each of the above-mentioned conditions, Archimedes' density measurements were performed on all the samples. An Acculab AST 224 Sartorius balance with an accuracy of $0.1 \mathrm{mg}$ equipped with a calibrated Sartorius Archimedes' kit was used for gravimetric measurements. A Keyence VHX-6000 optical microscope was used for surface roughness evaluation.

Optical microscopy was performed with Keyence VHX-6000 on ground, polished and etched samples. A2\% HF solution was used to etch Ti-6Al-4V samples to detect possible alpha case if present. 316L samples were electrochemically etched at $6 \mathrm{~V}$ DC with $10 \%$ oxalic acid solution.

Tensile tests were performed on an SIMADZU AG-X Plus machine according to ASTM E8M standard for quasi-static properties evaluation of the two materials 
Table 1 Mechanical properties, density and surface roughness of Ti-6Al-4V and 316L samples for different post-treatments

\begin{tabular}{l|l|l|l|l|l}
\hline \multicolumn{4}{|l|}{ Ti-6Al-4V } & \multicolumn{2}{l}{$316 \mathrm{~L}$} \\
\hline Heat treatment & ASB & \multicolumn{1}{l}{ SR } & HIP & ASB & SR \\
\hline$\sigma_{y}(\mathrm{MPa})$ & $1086 \pm 15$ & $926 \pm 45$ & $860 \pm 40$ & $453 \pm 7$ & $440 \pm 20$ \\
\hline$\sigma_{U T S}(\mathrm{MPa})$ & $1246 \pm 22$ & $1002 \pm 30$ & $960 \pm 30$ & $573 \pm 6$ & $570 \pm 30$ \\
\hline Elongation $(\%)$ & $11 \pm 1.0$ & $16 \pm 3.0$ & $18 \pm 4.0$ & $46 \pm 1.0$ & $49 \pm 5.0$ \\
\hline$\rho_{\text {rel }}$ density $(\%)$ & $99.61 \pm 0.05$ & $99.63 \pm 0.06$ & $99.71 \pm 0.14$ & $99.42 \pm 0.06$ & $99.42 \pm 0.05$ \\
\hline $\mathrm{R}_{\mathrm{a}}(\mu \mathrm{m})$ & $5.13 \pm 0.61$ & & $7.23 \pm 1.30$ & \\
\hline $\mathrm{R}_{\mathrm{v}}(\mu \mathrm{m})$ & $13.79 \pm 2.09$ & & $37.90 \pm 1.86$ & \\
\hline $\mathrm{R}_{\mathrm{z}}(\mu \mathrm{m})$ & $29.21 \pm 3.33$ & & $38.14 \pm 5.87$ & \\
\hline
\end{tabular}

when different post-treatments were considered. An Instron Electropuls E10000 with a $10 \mathrm{kN}$ load cell was used for all fatigue tests. The tests were force-controlled and were conducted with a constant amplitude fully reversed sinusoidal load (stress ratio $\mathrm{R}=-1$ ) with a frequency of $60 \mathrm{~Hz}$. Fatigue tests were performed on the five different batches until failure of the sample or stopped after $2 \times 10^{6}$ cycles. For each batch, at least three different stress levels were investigated and, for each stress level, at least two samples were tested.

Table 1 classifies the samples in terms of material, heat treatment, quasi-static mechanical properties, density and surface roughness.

A Philips XL 30 FEG scanning electron microscope (SEM) was used for crack initiation points identification on fractured samples.

\section{Results and Discussion}

\section{Relative Density}

The relative densities were measured by Archimedes' method and are reported in Table 1 . Ti-6Al-4V samples exhibit a low fraction of residual porosity with a relative density larger than $99.50 \%$, even in as-built condition. The HIP post-process slightly reduces the amount of residual porosity for Ti-6Al-4V. For 316L samples, the measured relative density was slightly below $99.50 \%$ both in as-built and stress-relieved conditions.

The process parameters used for sample production were standard parameter sets for LaserForm Ti gr 23(A). and LaserForm 316L(A). As a result, the amount of residual porosity generated during the manufacturing process was systematically below $0.6 \%$. 

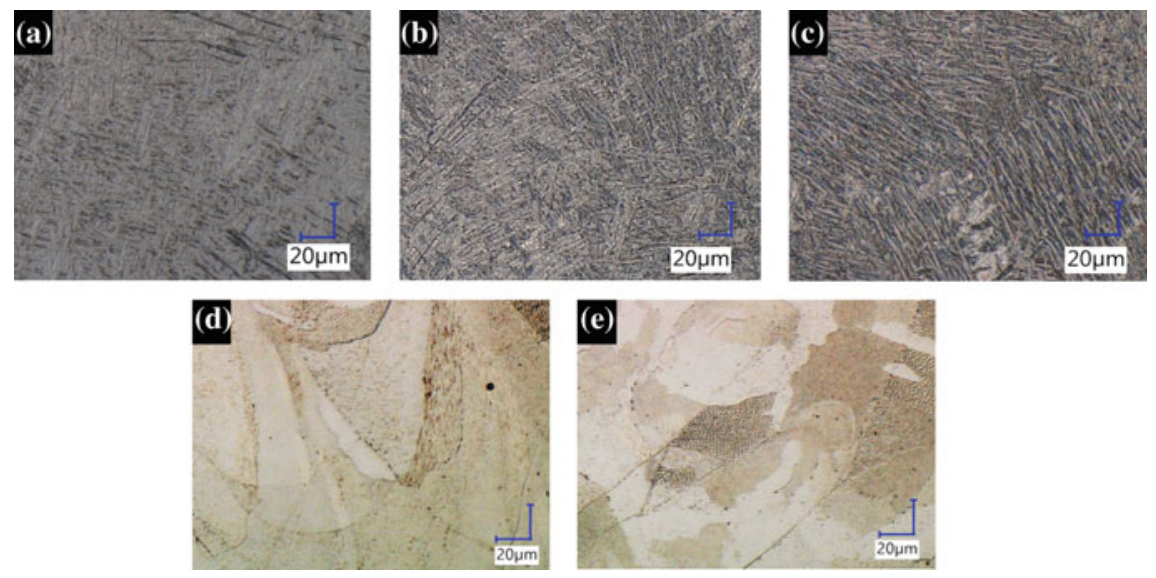

Fig. 2 Microstructure for Ti-6Al-4V-ASB (a), Ti-6Al-4V-SR (b), Ti-6Al-4V-HIP (c), $316 \mathrm{~L}-\mathrm{ASB}$ (d) and $316 \mathrm{~L}-\mathrm{SR}$ (e); cross section perpendicular to the building direction

\section{Microstructure Characterization}

Ti-6Al-4V exhibits an acicular martensitic microstructure in the as-built condition. Fine $\alpha^{\prime}$ martensite needles can be seen in Fig. 1a. Prior columnar $\beta$ grains were also observed along the building direction. Rapid cooling rates in SLM lead to such a typical process-induced martensitic microstructure [13]. A fine $\alpha+\beta$ lamellar microstructure is obtained after SR, as shown in Fig. 2b. This microstructure results from the decomposition of the $\alpha^{\prime}$ martensite to $\alpha+\beta$. Following HIP, the lamellar $\alpha$ $+\beta$ microstructure exhibits an even coarser morphology, as shown in Fig. 2c.

316L in as-built condition exhibits a typical cellular microstructure with clear distinction of melt pools as shown in Fig. 2d. A columnar grain growth pattern can also be observed, with grains growing across melt pool boundaries. Grain growth direction within the melt pool tends to follow the temperature gradient within the pool, starting from the periphery and growing towards the core. Stress-relief heat treatment did not induce any major microstructural change. A similar cellular microstructure is observed, as shown in Fig. 2e.

\section{Quasi-static Properties}

Tensile properties of the two materials including yield stress, ultimate tensile strength and elongation at break are reported in Table 1. From these results, different observations can be made for Ti-6Al-4V and 316L: (i) in as-built condition Ti-6Al-4V exhibits high strength and relatively low elongation (11\%); (ii) SR and HIP posttreatments improve elongation at break of $\mathrm{Ti}-6 \mathrm{Al}-4 \mathrm{~V}$ while reducing ultimate and 

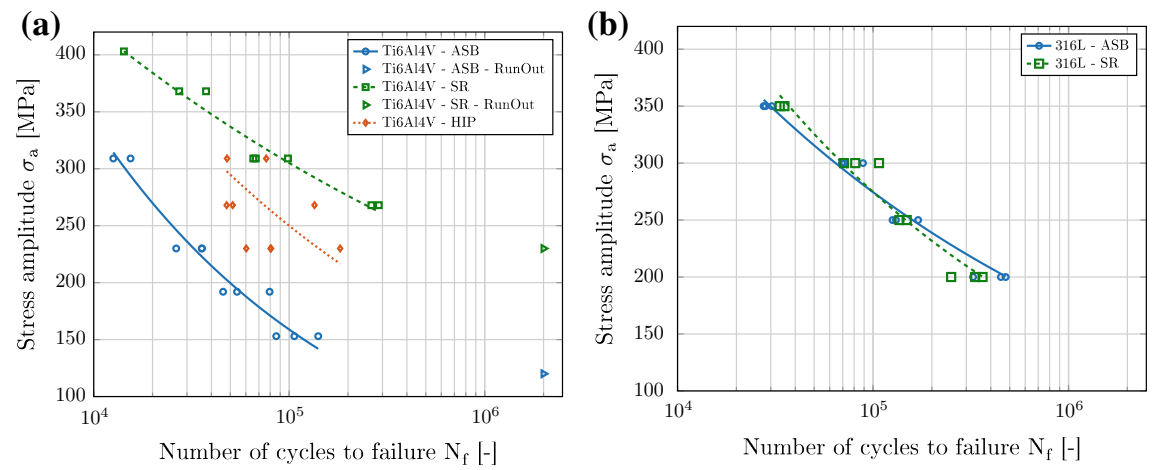

Fig. 3 Influence of post-treatments on fatigue properties of Ti-6Al-4V (a) $316 \mathrm{~L}$ (b) in as-built surface condition

yield strength; and (iii) 316L in stress-relieved condition exhibits similar yield and ultimate strength to those measured for the as-built material, with a slight (3\%) rise of the elongation at break.

It is well known [14] that in as-built SLM'ed Ti-6Al-4V, the martensitic microstructure is responsible for its relatively high strength and low ductility. With stress-relief and, to a larger extent, with HIP, the $\alpha^{\prime}$ microstructure coarsens into $\alpha+\beta$ lamellae, leading to a reduction in ultimate and yield stress and an increase in ductility. The coarser the grains (Fig. $2 b, c$ ), the more pronounced the abovementioned effect, which can be inferred from lowest strength and highest ductility of HIP'ed samples. With 316L, the SR heat treatment performed in order to relieve SLM-induced residual stresses did not cause much microstructural variations, as shown in Fig. 2d, e. Hence, the tensile properties observed after SR are comparable to those of as-built samples. This result also shows the limited dependence of $316 \mathrm{~L}$ tensile properties on the process-induced residual stresses.

\section{Fatigue Properties}

The tension-compression $(\mathrm{R}=-1)$ fatigue tests performed to evaluate the impact of post-treatments on Ti-6Al-4V and on 316L are presented, respectively, in Fig. 3a, b.

Figure 3a shows Ti-6Al-4V S-N curves evaluated for the three different conditions, namely, as-built, stress-relieved and HIP'ed. The graphs show that the two post-treatments, i.e. SR and HIP, improve the fatigue properties of Ti-6Al-4V samples. The poor fatigue property of as-built samples, compared with SR and HIP'ed samples, can be attributed to the presence of high residual stress levels generated during the L-PBF production process, as reported by Ramulu and Edwards [6] and to the brittle $\alpha^{\prime}$ martensitic microstructure [15]. 

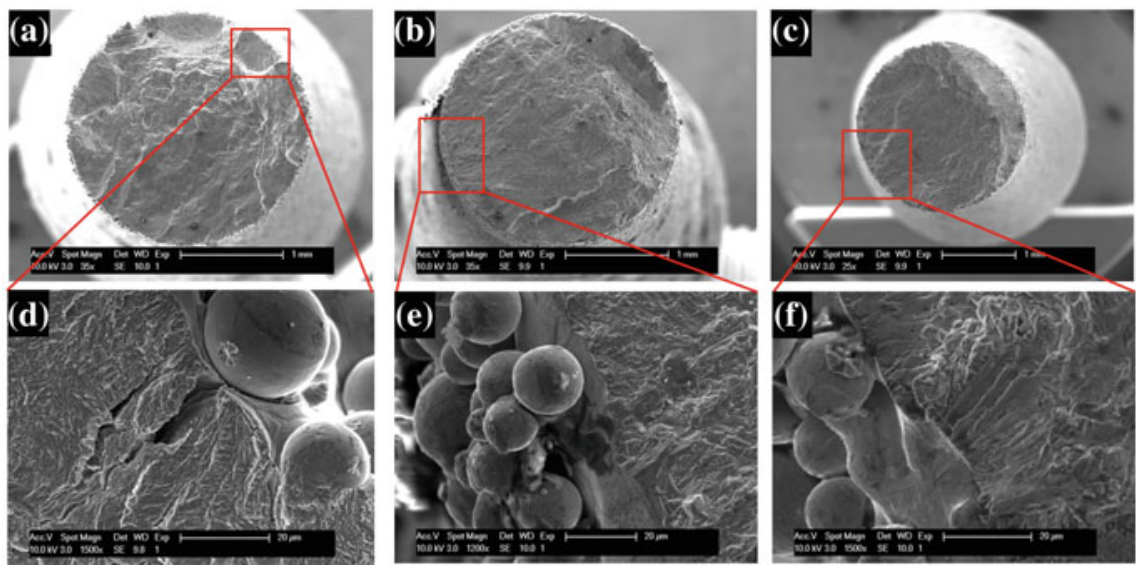

Fig. 4 SEM fractured surface pictures of Ti-6Al-4V samples in as-built (a, d), stress-relieved (b, e) and HIP'ed $(\mathbf{c}, \mathbf{f})$ conditions

The two heat treatments have different impacts on Ti-6Al-4V fatigue properties.

On the one hand, SR produces substantial improvement of Ti-6Al-4V fatigue properties. Relief of residual stresses can be considered an influencing factor for performance enhancement after SR [5]. The other factor responsible for the improvement can be the microstructure refinement of the $\alpha^{\prime}$ martensitic microstructure into a fine lamellar $\alpha+\beta$. In LCF fatigue regime crack initiation and propagation is influenced by $\alpha$ colony size in the $\alpha+\beta$ matrix. Small $\alpha$ colony sizes, to a certain extent, roughen the micro-crack front and hinder crack propagation, leading to improved fatigue lives [16]. Transformation from $\alpha^{\prime}$ martensitic microstructure to $\alpha+\beta$ lamella also increased the ductility of the material, which is, to some extent, beneficial for crack propagation resistance. Therefore, a lamellar $\alpha+\beta$ microstructure, relieved from residual stresses by SR, can lead to superior fatigue performance.

On the other hand, HIP does not represent a source of substantial fatigue improvement. Despite relieving residual stresses, HIP coarsens the microstructure (Fig. 2c) and leads to higher ductility with a slight reduction in tensile strength. Generally, a fine-grained microstructure exhibits good crack propagation resistance, whereas a coarse-grained microstructure offers good resistance against crack initiation [5]. However, the as-built rough surface with unfused powders (Fig. 4f), possesses multiple stress raisers acting as crack initiation sites. Coarsened microstructure after HIP can lead to a reduced resistance for crack propagation and lowered fatigue performance than SR. Kasperovich et al. [5] and Chastand et al. [17] observed enhanced fatigue behavior in Ti6Al4V after HIP than SR, the reason being closing of largesized pores within the samples. Since the samples used in this research were dense and devoid of such large-sized pores, fatigue results were not overshadowed by pores but mostly influenced by microstructural and surface factors. 
The fine lamellar microstructure (Fig. 2b) observed after SR, therefore, possesses an optimum balance between strength and ductility than the other two conditions. Since it is also justified by lamellar resistance to crack initiation and propagation, the chosen SR treatment has proved to be beneficial for fatigue behavior.

The analysis of Ti-6Al-4V fracture surfaces presented in Fig. 4a-c shows that the fatigue cracks always initiated from multiple points across the outer surface of the samples. Crack initiation points are associated with surface defects, such as unmolten particles, as shown in Fig. 4d-f. After the initiation, cracks propagate along the cross section of the sample until brittle failure occurs. This type of fatigue failure has been experienced for all the post-treatments investigated. It should be highlighted that during this investigation, all tested coupons failed because of surface defects, and none of the failure was due to the presence of internal defects.

From this analysis, several observations can be made: (i) the surface defects can be considered the main driver for crack initiation for all investigated conditions, i.e. as-built, SR and HIP, leading L-PBF Ti-6Al-4V to under-perform compared to conventionally manufactured Ti-6Al-4V [18]; (ii) heat treatments are beneficial in terms of fatigue performance since they reduce residual stresses [6] that could negatively influence the dynamic properties; (iii) microstructure evolution from the martensitic $\alpha^{\prime}$ (Fig. 2a) to a fine lamellar $\alpha+\beta$ (Fig. 2b) can have a beneficial impact on the fatigue properties of Ti-6Al-4V; (iv) however, further HIP-induced microstructure coarsening reduces the fatigue performance compared to SR.

The impact of a stress-relief post treatment on $316 \mathrm{~L}$ fatigue performances is presented in Fig. 3b. The graph shows that the SR post-treatment slightly influences the fatigue behavior of $316 \mathrm{~L}$ in as-built condition, leading to a small reduction in the slope of the 316L-SR S-N curve. For the two analyzed conditions, small data scatter was observed. Due to the high strength and the high ductility of AM'ed 316L, stress-raiser can be compensated; for this reason the material reaction to defects and residual stresses is relatively limited. Hence, a stress-relief operation does not induce significant changes in the S-N curves of Fig. 3b, as was also previously observed by Leuders et al. [19].

The analysis of the fractured surfaces reported in Fig. 5a, b highlights multiple crack initiations along the surface of the sample associated with surface defects generated during the manufacturing process. Similar to the observations in Ti-6Al-4V, the samples were nearly free of internal pores and defects, and cracks always initiated from the surface. 

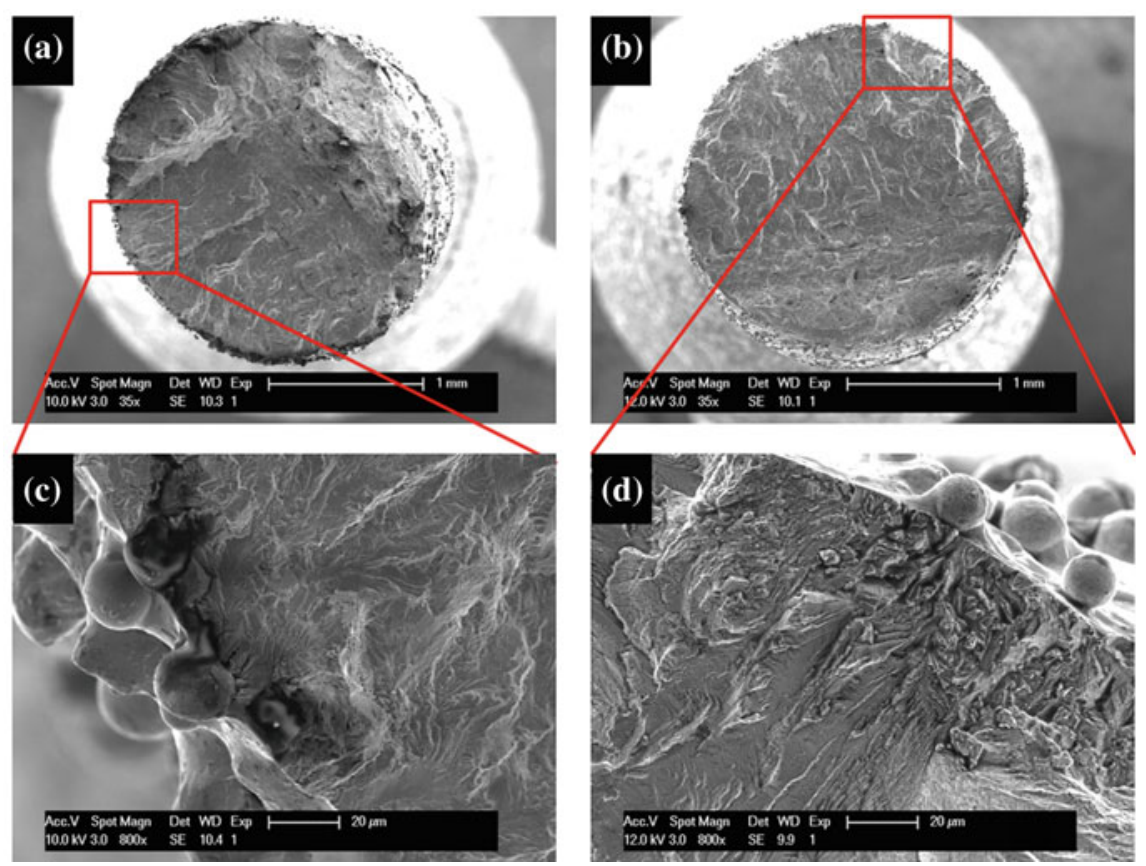

Fig. 5 SEM fractured surface pictures of 316L samples in as-built (a-c), stress-relieved (b-d)

\section{Conclusions}

The fatigue properties of Ti-6Al-4V and 316L produced by means of L-PBF were investigated on samples that received different heat treatments in as-built surface condition. Overall, the following conclusions can be drawn:

1. Stress-relief performed at $850{ }^{\circ} \mathrm{C}$ for $2 \mathrm{~h}$ significantly improves the fatigue properties of Ti-6Al-4V samples.

2. HIP does not improve the fatigue properties of high-quality $\mathrm{Ti}-6 \mathrm{Al}-4 \mathrm{~V}$ parts produced by L-PBF as much as a dedicated stress-relief treatment. In this study, the low residual porosity level generated during the production was only slightly reduced by HIP.

3. The production of almost fully dense parts can have a beneficial impact on the costs associated with the post treatments of Ti-6Al-4V AM'ed parts. In order to achieve desired mechanical properties, HIP can be replaced by an economically competitive stress relieving treatment.

4. Stress-relief performed at $470{ }^{\circ} \mathrm{C}$ for $5 \mathrm{~h}$ did not significantly change the fatigue properties of $316 \mathrm{~L}$ samples.

5. The samples used in this investigation were of high quality and almost pore-free test coupons; therefore, fatigue damages always occurred from surface defects 
identified as partially molten particles powder that create crack initiation favorable sites for both Ti-6Al-4V and 316L.

6. The surface defects have proven to be the main drivers for fatigue failure of high-quality L-PBF parts; therefore, further investigations are required to better understand the impact of roughness on fatigue of AM metals.

Acknowledgements The work leading to this publication has been funded by the SBO project "M3-FATAM" project (HBC.2016.0446), which fits in the MacroModelMat (M3) research program, coordinated by Siemens (Siemens PLM software, Belgium) and funded by SIM (Strategic Initiative Materials in Flanders) and VLAIO (Flanders Innovation \& Entrepreneurship Agency).

\section{References}

1. Kruth J-P, Levy G, Klocke F, Childs THC (2007) Consolidation phenomena in laser and powderbed based layered manufacturing. CIRP Ann Manuf Technol 56(2):730-759

2. DebRoy $\mathrm{T}$ et al (2018) Additive manufacturing of metallic components-process, structure and properties. Prog Mater Sci 92:112-224

3. Qiu C, Panwisawas C, Ward M, Basoalto HC, Brooks JW, Attallah MM (2015) On the role of melt flow into the surface structure and porosity development during selective laser melting. Acta Mater 96:72-79

4. Leuders $\mathrm{S}$ et al (2013) On the mechanical behaviour of titanium alloy TiAl6V4 manufactured by selective laser melting: fatigue resistance and crack growth performance. Int J Fatigue 48:300-307

5. Kasperovich G, Hausmann J (2015) Improvement of fatigue resistance and ductility of TiAl6V4 processed by selective laser melting. J Mater Process Technol 220:202-214

6. Edwards P, Ramulu M (2014) Fatigue performance evaluation of selective laser melted Ti-6Al-4V. Mater Sci Eng A 598:327-337

7. Cao F, Zhang T, Ryder MA, Lados DA (2018) A review of the fatigue properties of additively manufactured Ti-6Al-4V. JOM 70(3):349-357

8. Riemer A, Leuders S, Thöne M, Richard HA, Tröster T, Niendorf T (2014) On the fatigue crack growth behavior in 316L stainless steel manufactured by selective laser melting. Eng Fract Mech 120:15-25

9. Liverani E, Toschi S, Ceschini L, Fortunato A (2017) Effect of selective laser melting (SLM) process parameters on microstructure and mechanical properties of $316 \mathrm{~L}$ austenitic stainless steel. J Mater Process Technol 249:255-263

10. Spierings AB, Wegener K, Starr TL (2013) Fatigue performance of additive manufactured metallic parts. Rapid Prototyp J 19(2):88-94

11. Zhang M, Li H, Zhang X, Hardacre D (2016) Review of the fatigue performance of stainless steel 316L parts manufactured by selective laser melting

12. Kranz J, Herzog D, Emmelmann C (2014) Design guidelines for laser additive manufacturing of lightweight structures in TiA16V4. J Laser Appl 27(S1):S14001

13. Thijs L, Verhaeghe F, Craeghs T, Humbeeck JV, Kruth J-P (2010) A study of the microstructural evolution during selective laser melting of Ti-6Al-4V. Acta Mater 58(9):3303-3312

14. Vrancken B, Thijs L, Kruth J-P, Van Humbeeck J (2012) Heat treatment of Ti6Al4V produced by selective laser melting: microstructure and mechanical properties. J Alloy Compd 541:177-185

15. Xu W, Sun S, Elambasseril J, Liu Q, Brandt M, Qian M (2015) Ti-6Al-4V additively manufactured by selective laser melting with superior mechanical properties. JOM 67(3):668-673

16. Lütjering $G$ (1998) Influence of processing on microstructure and mechanical properties of $(\alpha+\beta)$ titanium alloys. Mater Sci Eng A 243(1):32-45 
17. Chastand V, Tezenas A, Cadoret Y, Quaegebeur P, Maia W, Charkaluk E (2016) Fatigue characterization of titanium Ti-6Al-4V samples produced by additive manufacturing. Proc Struct Integr 2:3168-3176

18. Li P, Warner DH, Fatemi A, Phan N (2016) Critical assessment of the fatigue performance of additively manufactured $\mathrm{Ti}-6 \mathrm{Al}-4 \mathrm{~V}$ and perspective for future research. Int $\mathrm{J}$ Fatigue 85:130-143

19. Leuders S, Lieneke T, Lammers S, Tröster T, Niendorf T (2014) On the fatigue properties of metals manufactured by selective laser melting - the role of ductility. J Mater Res 29(17):1911-1919 